\title{
Iron Loss and Magnetic Hysteresis Properties of Nanocrystalline Ring Core at High and Room Temperatures Under Inverter Excitation
}

\author{
A. Yao, R. Moriyama, and T. Hatakeyama \\ Department of Electrical and Computer Engineering, Toyama Prefectural University, 5180, Kurokawa, Imizu 939-0398, Japan
}

This paper discusses the iron loss and magnetic hysteresis properties of a ring core of nanocrystalline magnetic materials (NMM) at room temperature (RT) and high temperature (HT) under pulse-width-modulation (PWM) inverter excitation. As in the case of the DC hysteresis loop, the coercivity of the NMM ring core at $300^{\circ} \mathrm{C}(\mathrm{HT})$ under PWM inverter excitation is larger than that at RT, mainly because of weakening of intergranular magnetic coupling at HT. In addition, in the NMM ring core, the area of the minor loops at HT increases compared with that at RT. Iron loss in the NMM core fed by the PWM inverter increases in tandem with an increase in temperature. Hysteresis loss increases dramatically in tandem with an increase in temperature for every tested case. In a low carrier frequency region, the eddy current loss at $300^{\circ} \mathrm{C}$ increases.

Key words: Nanocrystalline magnetic materials, high temperatures, iron loss, magnetic hysteresis property, inverter

\section{Introduction}

High temperature (HT) motor systems have been extensively studied $^{1-6)}$. Motors are generally driven by a pulse-widthmodulation (PWM) inverter to control torque and rotational speed. PWM inverter outputs have higher harmonic components superimposed in fundamental waveforms. Many studies have reported that, due to high harmonic components, iron loss of the motor core under PWM inverter excitation increases ${ }^{7-17)}$ by $10 \%-50 \%^{10)}$ compared with sinusoidal excitation. In these researches, magnetic hysteresis loops had many minor loops. Thus, it was important to accurately measure and simulate the magnetic hysteresis and iron loss properties. Recently, we have shown that iron loss of conventional non-oriented (NO) electrical steel sheets and amorphous magnetic materials (AMM) excited by PWM inverter decreases in tandem with an increase in temperature ${ }^{4,6)}$. Previous studies have also shown that in NO sheets and AMM, the area of minor loops in hysteresis loops diminishes as the temperature increases ${ }^{4,6}$. This study focuses on the temperature dependence of iron loss and the magnetic hysteresis properties of nanocrystalline magnetic materials (NMM) under PWM inverter excitation.

Recently, motor cores made of $\mathrm{NMM}^{18,19)}$ have been developed to reduce the iron loss of the motor system ${ }^{15,20-22)}$. We have shown that the NMM motor is suitable for use in high-speed (HS) and high-frequency regions ${ }^{22)}$. When HS motor systems are used, the magnetic properties of the motor core (magnetic materials) are affected by heat. Thus, as basic research to develop high-efficiency motors in HS and HT regions, it is necessary to accurately investigate the magnetic properties of the NMM core at HT under inverter excitation in experiments and numerical calculations.

This paper discusses the iron loss and magnetic hysteresis properties of NMM ring core at room temperature (RT) and HT under a single-phase full-bridge PWM inverter excitation.
We experimentally and numerically examined the impact of temperature on iron loss and hysteresis (major and minor ${ }^{4)}$ ) loops. This paper reports on hysteresis and eddy current losses of NMM ring at RT and HT under PWM inverter excitation.

\section{Experimental and Numerical Methods}

Figure 1 shows the configuration of the NMM ring specimen and its measurement system. The ring specimen is composed of NMM (FT-3M), cut into a ring shape by wire electric discharge machining ${ }^{16)}$. The height, inner diameter, and outer diameter of the ring core of NMM are 7, 102, and $127 \mathrm{~mm}$, respectively ${ }^{4,6,16)}$. The space factor $\xi_{\text {sf }}$ of the NMM ring core is approximately $87.3 \%$. In this research, the exciting coil was wound around the ring specimen and the $B$-coil was used to measure the magnetic flux density. The ring specimen was set in the oven (ESPEC Corp., STH-120) to examine the impact of temperature on the iron loss and magnetic hysteresis properties ${ }^{4)}$ of NMM core under PWM inverter excitation.

To apply the PWM waveform to the NMM ring specimen, we used a single-phase PWM inverter (Myway Plus Corp., MWINV9R122C). Our measurement system had a high-performance A/D converter (NI Corp., PXIe-5163, 14 bit, $50 \mathrm{MS} / \mathrm{s}$ ), a current probe (HIOKI E.E. Corp., CT6711), and a voltage probe (Iwatsu Electric Co., Ltd., SS-320). The fundamental frequency, the dead time, and the modulation index were $50 \mathrm{~Hz}, 3.5 \mu \mathrm{s}$, and 0.7 , respectively. The maximum magnetic flux density $\left(B_{\max }\right)$ was set to $0.8 \mathrm{~T}$. The carrier frequency $\left(f_{\mathrm{c}}\right)$ was set to $1,4,12$, or $20 \mathrm{kHz}$.

By using the magnetic flux density $(B)$ and the magnetic field intensity $(H)$, the iron loss ( $W_{\text {ring }}$ ) of the NMM ring specimen is represented as ${ }^{17}$

$$
W_{\text {ring }}=\frac{1}{T \rho} \int H \mathrm{~d} B,
$$

where $T(=0.02 \mathrm{~s})$ denotes the period and $\rho\left(=7300 \mathrm{~kg} / \mathrm{m}^{3}\right)$ is the density of NMM. In this research, $B$ and $H$ were given 
as $\int V d t /\left(N_{2} S \xi_{\mathrm{sf}}\right)$ and $N_{1} I / l$, respectively, where $V$ denotes the voltage induced in the $B$-coil, $N_{2}(=100)$ is the number of turns of $B$-coil, $S\left(=87.5 \mathrm{~mm}^{2}\right)$ is the cross-section of the NMM core, $N_{1}(=100)$ is the number of turns in the exciting coil, $I$ is the current flowing in the exciting coil, and $l(=0.36 \mathrm{~m})$ is the magnetic path length.

By using the dynamic hysteresis model that combines the play model with the Cauer circuit ${ }^{4-6,23-28)}$, we calculated the numerical hysteresis loops of the NMM ring under PWM inverter excitation. In our simulations, the hysteresis loops, $H(B)$, were calculated by ${ }^{6,26)}$

$$
\begin{array}{r}
H(B)=H_{\mathrm{DC}}(B)+\alpha \sigma d^{2} \frac{7\left(B^{k}-B^{k-1}\right)+2 L^{\prime} h_{2}^{k-1}}{84 \Delta t+2 \alpha \sigma d^{2} L^{\prime}} \\
+\alpha \sigma d^{2} \frac{3 L^{\prime}\left(h_{2}^{k}-h_{2}^{k-1}\right)}{420 \Delta t},
\end{array}
$$

where $\sigma$ denotes the electrical conductivity, $H_{\mathrm{DC}}(B)$ is the DC hysteresis loops simulated by the play model, $k$ is the step number, $d(=18 \mu \mathrm{m})$ is the thickness of NMM, and $\Delta t$ is the time division. Moreover, $\sigma$ at $\mathrm{RT}$ and $300^{\circ} \mathrm{C}$ is $8.33 \times 10^{5}{ }^{29)}$ and $7.27 \times 10^{5} \mathrm{~S} / \mathrm{m}$, respectively, which were obtained by the method of Ref. ${ }^{30)}$. Meanwhile, $\alpha$ and $L^{\prime}$ and are fitting parameters. Each experimental DC hysteresis loop at RT and $300^{\circ} \mathrm{C}$, as in the example shown in Fig. 2, was utilized in our numerical simulations (see Refs. ${ }^{4-6,26)}$ for more detail).

This paper reports on hysteresis and eddy current losses of NMM ring at RT and HT under PWM inverter excitation. These hysteresis and eddy current losses were obtained based on our reported method ${ }^{6)}$ of the loss repartition between eddy current and hysteresis losses. As the loss repartition between eddy current and hysteresis losses, we performed the following three steps:

(1) Numerical iron losses were fitted to experimental results,

(2) Hysteresis loss was calculated at $\sigma=0$ with Eq. (2) in numerical simulations, and

(3) Eddy current loss was calculated by subtracting the hysteresis loss from the total iron loss.

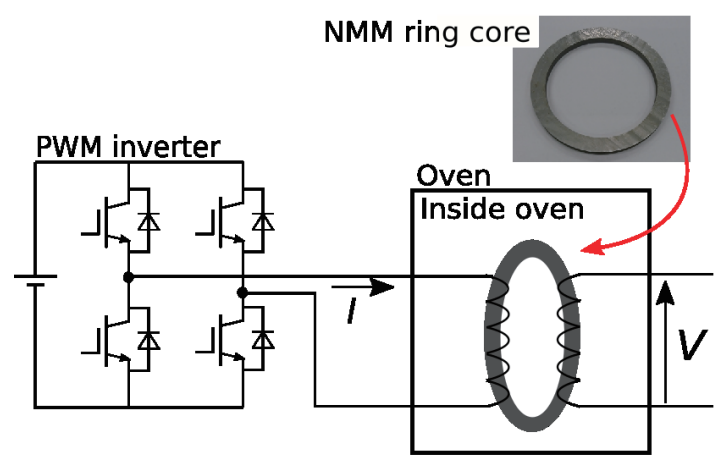

Fig. 1 NMM ring specimen and its measurement system (see Refs. ${ }^{4-6,16)}$ for more details).

\section{Results and Discussion}

Figure 2 shows the DC hysteresis loops at RT and $300^{\circ} \mathrm{C}$ under sinusoidal excitation. In our study, the DC hysteresis loops were obtained based on the method of Ref. ${ }^{26)}$. The NMM ring core had a hysteresis loss of $1.02 \mathrm{~mJ} / \mathrm{kg}$ at RT $\left(1.66 \mathrm{~mJ} / \mathrm{kg}\right.$ at $\left.300^{\circ} \mathrm{C}\right)$ and at $B_{\max }=0.8 \mathrm{~T}$. The intergranular magnetic coupling at HT weakened and then the coercivity at HT enlarged, compared with the case at $\mathrm{RT}^{31-33)}$. Therefore, the hysteresis loss of the NMM ring core increased in tandem with an increase in temperature.

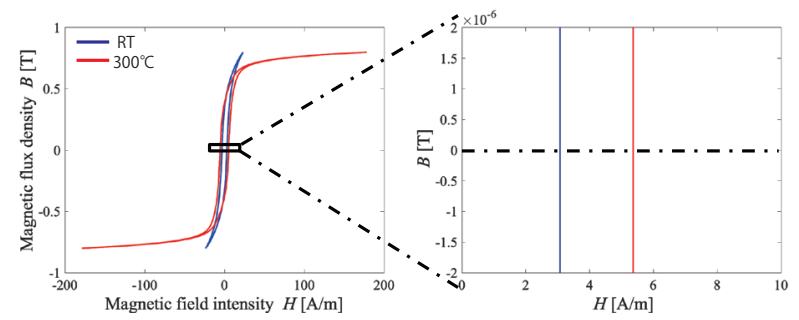

Fig. 2 Representative DC hysteresis loops of the NMM ring core at $B_{\max }=0.8 \mathrm{~T}$. In our numerical simulations, the DC hysteresis loops every $0.02 \mathrm{~T}$ were used as input (see Refs. ${ }^{4-6,26)}$ for more detail on numerical simulations).

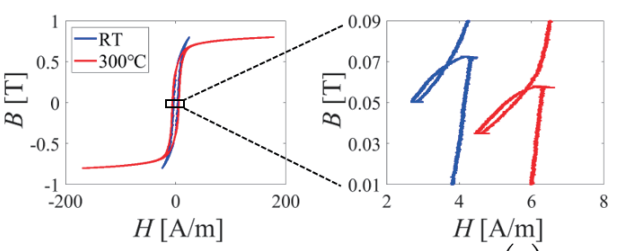

(a)

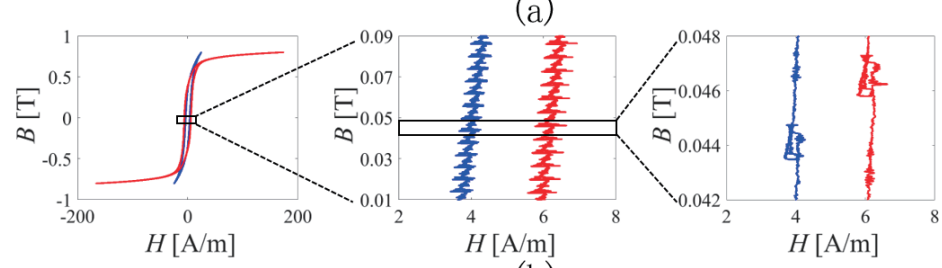

(b)

Fig. 3 Experimental hysteresis loops excited by PWM inverter, as shown in Fig. 1, at (a) $f_{\mathrm{c}}=1 \mathrm{kHz}$ and (b) $f_{\mathrm{c}}=20 \mathrm{kHz}$.

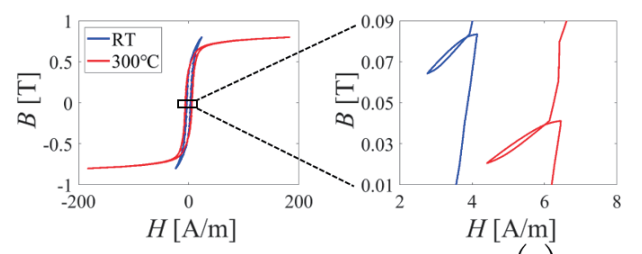

(a)

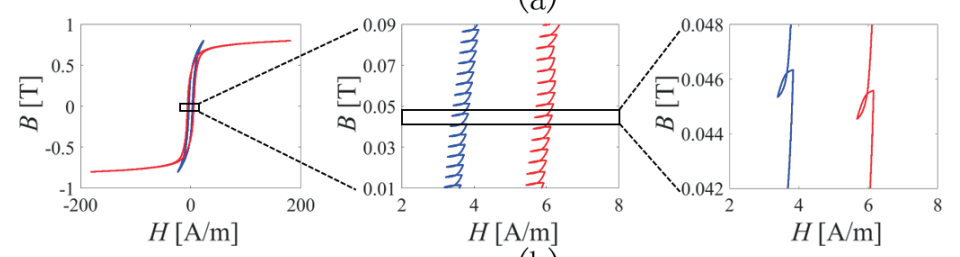

(b)

Fig. 4 Numerical hysteresis loops generated from Eq. (2) under PWM inverter excitation at (a) $f_{\mathrm{c}}=1 \mathrm{kHz}$ and (b) $f_{\mathrm{c}}=20 \mathrm{kHz}$. 


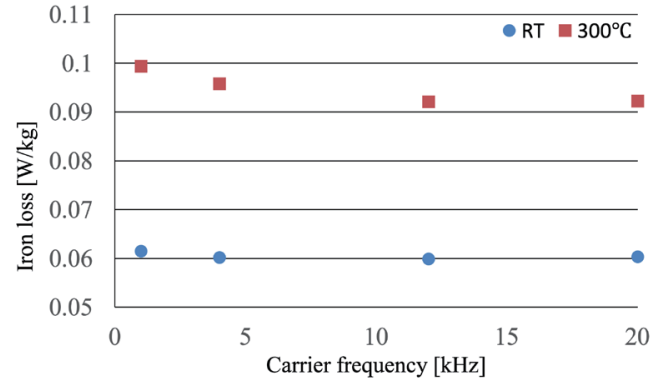

Fig. 5 Carrier frequency dependence of iron losses of NMM ring core at RT and $300^{\circ} \mathrm{C}$, excited by the PWM inverter waveform.
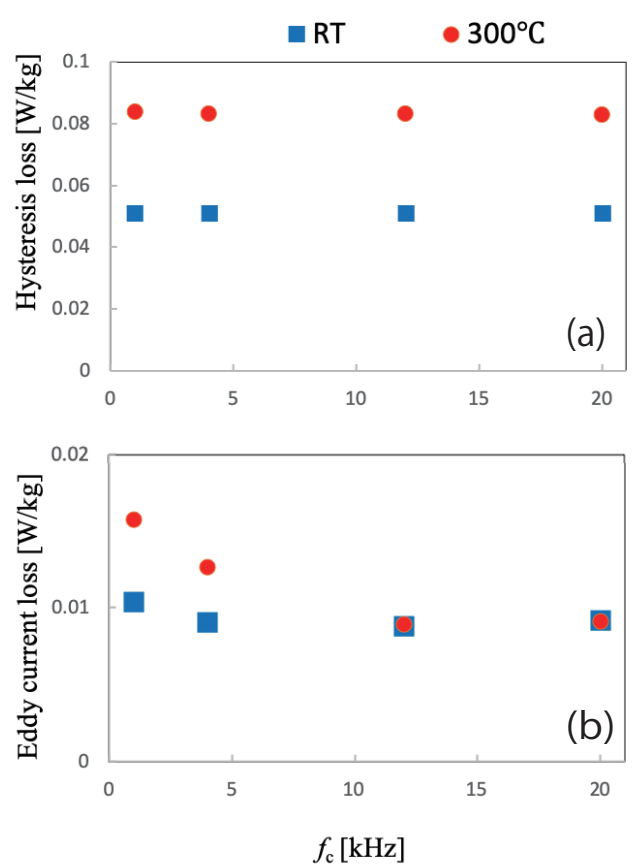

Fig. 6 (a) Hysteresis and (b) eddy current losses at different carrier frequency values.

Figure 3 shows the experimental hysteresis loops of the NMM ring core at RT and $300^{\circ} \mathrm{C}$ excited by the PWM inverter waveform. The carrier frequencies of Figs.(a) and (b) are 1 and 20 $\mathrm{kHz}$, respectively. The iron losses at $\mathrm{RT}$ and $300^{\circ} \mathrm{C}$ are around 0.61 and $0.99 \mathrm{~W} / \mathrm{kg}(0.60$ and $0.92 \mathrm{~W} / \mathrm{kg})$ at $f_{\mathrm{c}}=1 \mathrm{kHz}\left(f_{\mathrm{c}}=\right.$ $20 \mathrm{kHz}$ ), respectively. The coercivity of the NMM ring core at $300^{\circ} \mathrm{C}$ under PWM inverter excitation is larger than that at RT, mainly because, as in the case of the DC hysteresis loop, the intergranular magnetic coupling at HT weakened. Previous studies have shown that the iron loss of NO and AMM ring cores fed by the PWM inverter decreases in tandem with an increase in temperature ${ }^{4,6)}$. However, the iron loss of the NMM core excited by the PWM inverter increases in tandem with an increase in temperature.

The enlarged figures show that when the temperature of the NMM ring core increases, the width and the height of the minor loops increase, especially at $f_{\mathrm{c}}=1 \mathrm{kHz}$. In other words, the area of the minor loop of the NMM ring core at $300^{\circ} \mathrm{C}$ is larger than that at RT. The area of the minor loop at RT and $300^{\circ} \mathrm{C}$ is 3.05 and $4.52 \mathrm{~mW} / \mathrm{kg}(1.80$ and $1.83 \mathrm{~mW} / \mathrm{kg})$ at $f_{\mathrm{c}}=1 \mathrm{kHz}\left(f_{\mathrm{c}}=20\right.$ $\mathrm{kHz}$ ). Previous studies have shown that, in a ring core made of NO sheets and AMM, the area of the minor loop at HT is smaller than that at $\mathrm{RT}^{4,6)}$. However, in the NMM ring core, the area of the minor loops at $\mathrm{HT}$ is greater than that at RT because $H$ of the major loop at $300^{\circ} \mathrm{C}$ is greater than that at RT, as shown in Fig. 3 and then, the variation in $H$ of the minor loop at $300^{\circ} \mathrm{C}$ enlarges, especially at $f_{\mathrm{c}}=1 \mathrm{kHz}$. At $f_{\mathrm{c}}=20 \mathrm{kHz}$, the area of the minor loop at RT and HT has almost the same values.

Figure 4 shows the hysteresis loops calculated by Eq. (2) for $f_{\mathrm{c}}$ $=1 \mathrm{kHz}$ and $f_{\mathrm{c}}=20 \mathrm{kHz}$. The calculated iron losses were fitted to the measured values by using the fitting parameters ${ }^{5,6)}$. Both experimental and numerical hysteresis loops have almost the same behavior. It is considered that the slight differences between experimental and numerical loops are caused by neglecting dead time, ringing noises, and so on, in the numerical simulations ${ }^{17)}$.

Figure 5 shows the carrier frequency dependence of iron loss at $\mathrm{RT}$ and $300^{\circ} \mathrm{C}$ when the NMM ring core is excited with the inverter waveform. When the temperature of the NMM ring core increases, iron loss increases for every tested case.

Figure 6 shows the calculated hysteresis and eddy current loss at different carrier frequency values. In this research, the red and blue points showed the losses at RT and at $300^{\circ} \mathrm{C}$. The hysteresis loss increased dramatically in tandem with an increase in temperature for all tested carrier frequencies. Under these experimental conditions, the ratio of hysteresis loss to total loss was high in the HT region. In a low carrier frequency region (< about $10 \mathrm{kHz}$ ), the eddy current loss at $300^{\circ} \mathrm{C}$ increased compared with that at RT, mainly because the area of the minor loop at HT was larger than that at RT, as shown in Figs. 3(a) and 4(a). In a high carrier frequency region ( $>$ about $10 \mathrm{kHz}$ ), the eddy current losses at RT and at $300^{\circ} \mathrm{C}$ had almost the same values. It is considered that, arising from the skin effect, this situation occurs mainly because the ratio of eddy current loss to the total iron loss of the NMM ring core in the high carrier frequency region is relatively low compared with that in the low carrier frequency region. Moreover, the area of the minor loop of the NMM ring core at RT and HT has almost the same values, as shown in Figs. 3(b) and 4(b). Thus, in the high carrier frequency region, an increase in total iron loss at HT depends strongly on an increase in hysteresis loss. To achieve a high-efficiency motor system at HT and HS, a design that reduces hysteresis loss and the reduction of eddy current losses by using high carrier frequencies must be considered.

\section{Conclusion}

For the first time, we examined the iron loss and magnetic hysteresis properties of the NMM ring core at RT and HT under a single-phase PWM inverter excitation. We confirmed that the iron loss of the NMM ring core under PWM inverter excitation 
increases in tandem with an increase in temperature because of weakening of intergranular magnetic coupling at HT. Both the experiments and numerical simulations showed that the area of the minor loop of the NMM ring core at HT is larger than that at RT, especially in a low carrier frequency region. Based on experimental and numerical results, we showed that the hysteresis loss increases dramatically in tandem with an increase in temperature for all tested carrier frequencies. It was shown that the eddy current loss at $300^{\circ} \mathrm{C}$ increases compared with that at RT, mainly because the area of the minor loop at HT is larger than that at RT. In the future we will examine the loss ratio between major and minor loops.

Acknowledgments This work was partly supported by the JSPS KAKENHI $\sharp 18$ K13749, JST OPERA $\sharp J P M J O P 1841$, JFE 21st Century Foundation, Kansai Research Foundation, Takeuchi Foundation, and Nagamori Foundation Research Grant.

\section{References}

1) L. Burdet: Ph.D. dissertation, Citeseer (2006).

2) T. D. Kefalas and A. G. Kladas: IEEE Trans. Ind. Electron., 61, 4404 (2014).

3) A. Yao, A. Adachi, and K. Fujisaki: Proc. IEMDC, 1 (IEEE, 2017).

4) A. Yao, S. Odawara, and K. Fujisaki: IEEJ J. Ind. Appl., 7, 298 (2018).

5) A. Yao and T. Hatakeyama: J. Magn. Soc. Jpn., 43, 46 (2019).

6) A. Yao: J. Magn. Soc. Jpn., 44, 2003L002 (2020).

7) A. Boglietti, P. Ferraris, M. Lazzari, and F. Profumo: IEEE Trans. Magn., 27, 5334 (1991).

8) A. Boglietti, P. Ferraris, M. Lazzari, and M. Pastorelli: IEEE Trans. Magn., 31, 4250 (1995).

9) M. Kawabe, T. Nomiyama, A. Shiozaki, H. Kaihara, N. Takahashi, and M. Nakano: IEEE Trans. Magn., 48, 3458 (2012).

10) K. Fujisaki and S. Liu: J. Appl. Phys., 115, 17A321 (2014).

11) A. Yao, K. Tsukada, S. Odawara, K. Fujisaki, Y. Shindo, N. Yoshikawa, and T. Yoshitake: AIP Adv., 7, 056618 (2017).

12) A. Yao and K. Fujisaki: Proc. LDIA2017, 1 (IEEJ, 2017).

13) A. Yao, K. Tsukada, and K. Fujisaki: IEEJ J. Ind. Appl., 7,
$321(2018)$

14) A. Yao, T. Sugimoto, S. Odawara, and K. Fujisaki: AIP Adv., 8, 056804 (2018).

15) A. Yao, T. Sugimoto, S. Odawara, and K. Fujisaki: IEEE Trans. Magn., 54, 1 (2018).

16) A. Yao, T. Sugimoto, and K. Fujisaki: IEEJ J. Ind. Appl., 139, 276 (2019) (in Japanese).

17) A. Yao, T. Funaki, and T. Hatakeyama: J. Magn. Soc. Jpn., 43, 105 (2019).

18) Y. Yoshizawa and K. Yamauchi: Mater. Trans., JIM, 31, 307 (1990).

19) A. Yao, M. Inoue, K. Tsukada, and K. Fujisaki: AIP Adv., 8, 056640 (2018).

20) N. Nishiyama, K. Tanimoto, and A. Makino: AIP Adv., 6, 055925 (2016).

21) N. Denis, M. Inoue, K. Fujisaki, H. Itabashi, and T. Yano: IEEE Trans. Magn., 53, 1 (2017).

22) A. Yao, T. Sugimoto, and K. Fujisaki: J. Magn. Soc. Jpn., 43, 42 (2019).

23) J. H. Krah: IEEE Trans. Magn., 41, 1444 (2005).

24) Y. Shindo and O. Noro: IEEJ Trans. Fund. Mater., 134, 173 (2014).

25) Y. Shindo, T. Miyazaki, and T. Matsuo: IEEE Trans. Magn., 52, 1 (2016).

26) S. Odawara, K. Fujisaki, T. Matsuo, and Y. Shindo: IEEJ Trans. Ind. Appl., 135, 1191 (2015).

27) T. Miyazaki, T. Mifune, T. Matsuo, Y. Shindo, Y. Takahashi, and K. Fujiwara: J. Appl. Phys., 117, 17D110 (2015).

28) S. Odawara and K. Fujisaki: IEEE Trans. Magn., 54, 1 (2018).

29) Nanocrystalline soft magnetic material catalog No. hl-fm9-h Hitachi Metals, Ltd., (in Japanese).

30) R. Moriyama, A. Yao, and T. Hatakeyama: The papers of Technical Meeting, MAG, IEE Japan, MAG-19-203, 35 (2019) (in Japanese).

31) G. Herzer: IEEE Trans. Magn., 25, 3327 (1989).

32) K. Suzuki, A. Makino, A. Inoue, and T. Masumoto: J. Magn. Soc. Jpn., 18, 800 (1994) (in Japanese).

33) K. Suzuki: J. Magn. Soc. Jpn., 24, 495 (2000) (in Japanese).

Recieved Jan. 8, 2020; Accepted Feb. 4, 2020 